\title{
Prochloraz causes irreversible masculinization of zebrafish (Danio rerio)
}

\author{
Lisa Baumann • Susanne Knörr • Susanne Keiter • \\ Tina Nagel • Helmut Segner • Thomas Braunbeck
}

Received: 30 June 2014 / Accepted: 18 August 2014 / Published online: 28 August 2014

(C) Springer-Verlag Berlin Heidelberg 2014

\begin{abstract}
The aim of the present study was to investigate the persistence of endocrine effects by prochloraz, a fungicide known to have multiple effects on the endocrine system of vertebrates. Since discontinuous exposure is particularly relevant in aquatic ecosystems, an exposure scenario with an exposure phase and a subsequent recovery period was chosen to assess the potential for reversibility of effects by prochloraz on the sexual development of zebrafish (Danio rerio). Zebrafish were exposed to different concentrations of prochloraz $(10-300 \mu \mathrm{g} / \mathrm{L})$ until 60 days post hatch (dph), which includes the period of sexual differentiation. For the subsequent 40 days, fish were either held in clean water for depuration or under further continuous exposure. Histological investigations of the gonads revealed persistent effects on sexual differentiation. The sex ratio was skewed towards males and significantly more intersex individuals were found
\end{abstract}

\footnotetext{
Responsible editor: Philippe Garrigues

L. Baumann $(\bowtie) \cdot$ H. Segner

Centre for Fish and Wildlife Health, Vetsuisse Faculty,

University of Bern, PO Box 8466, CH-3001 Bern, Switzerland

e-mail: lisa.baumann@vetsuisse.unibe.ch

H. Segner

e-mail: helmut.segner@vetsuisse.unibe.ch

L. Baumann · S. Knörr · S. Keiter · T. Nagel · T. Braunbeck Aquatic Ecology and Toxicology Section, Centre for Organismal Studies, University of Heidelberg, Im Neuenheimer Feld 504, 69120 Heidelberg, Germany

S. Knörr

e-mail: susanne.knoerr@gmx.de

S. Keiter

e-mail: susanne.keiter@cos.uni-heidelberg.de

T. Nagel

e-mail: tina.nagel@stud.uni-heidelberg.de

T. Braunbeck

e-mail: braunbeck@uni-hd.de
}

after exposure to prochloraz at $60 \mathrm{dph}$. No intersex fish, but masculinized sex ratios were still present after the depuration period, documenting that prochloraz irreversibly affects the sexual development of zebrafish.

Keywords Zebrafish · Gonad histology · Sexual differentiation · Endocrine disruptor · Aromatase inhibitor . Fungicide

\section{Introduction}

Exposure of wildlife and humans to endocrine-disrupting chemicals (EDCs) represents a serious hazard for reproductive capacities of individuals and, thus, population fitness. Agriculture continuously and significantly contributes to the pollution of the environment via the use of fertilizers and pesticides. Especially aquatic organisms are massively affected, either by periodic peak exposures or chronic low-dose exposures. Prochloraz is a popular imidazole fungicide inhibiting the biosynthesis of ergosterol, which is part of the cell membrane in many fungi (Johnston et al. 1996). Imidazole derivatives are, therefore, widely used as antifungal agents not only in agriculture, but also in textile- and paint-producing industries. Through these applications, they can reach the environment and accumulate in aquatic organisms and their predators (reviewed by Mnif et al. 2011). Data on environmental concentrations suggest that environmentally realistic prochloraz concentrations in European surface waters are generally below $1 \mu \mathrm{g} / \mathrm{L}$ (Weltje 2013). A recent study reports average concentrations of $76.04 \mathrm{ng} / \mathrm{L}$ at different sample sites of the Jucar River, Spain (Belenguer et al. 2014). Other studies indicate a causal relation between human exposure to pesticides and poor sperm quality (Swan et al. 2003) or increased incidence of cryptorchidism in sons of female gardeners (Weidner et al. 1998). Although several studies reported significant effects of 
prochloraz on fish and other vertebrates, the underlying mechanisms are diverse and not yet fully understood. Prochloraz antagonizes the androgen and the estrogen receptors agonizes the $\mathrm{Ah}$ receptor and inhibits aromatase activity (reviewed by Vinggaard et al. 2006). Moreover, oocyte maturation can be triggered by prochloraz by the induction of luteinizing hormone (LH)-related genes (Rime et al. 2010). There are also indications that prochloraz has adverse effects on the thyroid system of vertebrates (Brande-Lavridsen et al. 2010; Liu et al. 2011). In zebrafish (Danio rerio), masculinization and inhibited vitellogenin (VTG) production have been reported, as well as increased numbers of intersex individuals and inhibited gonad maturation (Baumann et al. 2008, 2013; Holbech et al. 2012; Kinnberg et al. 2007; Thorpe et al. 2011). In an 8-day exposure experiment with adult fathead minnow (Pimephales promelas), Ankley et al. (2009) found multiple alterations such as inhibition of estradiol and testosterone production. These effects were compensated within a short recovery period of 8 days, indicating that the effects of prochloraz on the hormonal system are not persistent in adult fish. In contrast, in juvenile (developing) fish, the reversibility of prochloraz-induced effects has not been investigated. Therefore, the aim of the present study was to examine the persistence of adverse effects of prochloraz on zebrafish gonad development by means of an exposure scenario including prolonged exposure followed by a recovery period.

\section{Materials and methods}

\section{Test substance}

Prochloraz (CAS-No.: 67747-09-5) was obtained from Sigma-Aldrich (Deisenhofen, Germany). The following test concentrations were used for the exposure of zebrafish: 10,30, 100 , and $300 \mu \mathrm{g} / \mathrm{L}$. Stock solutions were produced by dissolving prochloraz in warm deionized water $\left(40^{\circ} \mathrm{C}\right)$, stirred over night without solvent. Fresh stock solutions were produced every second day before use in light-isolated glass reservoirs, from which they were added to the exposure tanks via peristaltic pumps (MINIPULS 3, Gilson; Limburg, Germany).

\section{Exposure and sampling}

The exposure of zebrafish (D. rerio, Westaquarium strain) to prochloraz started, at latest, 1-h post fertilization (hpf) and ended at 100 days post hatch (dph). Fish were held in aerated 12-L flow-through glass tanks at $27 \pm 1{ }^{\circ} \mathrm{C}$ and a dark-light cycle of 10/14 h. Temperature and flow-through rate (complete water exchange every $8 \mathrm{~h}$ ) were controlled twice daily. Further parameters like hardness (200-280 mg/L), conductivity (600-750 $\mu \mathrm{S}), \mathrm{pH}(8.0-8.2)$, and oxygen saturation (90-95\%) were controlled at least once weekly. Feces and food leftovers were removed daily. From days 4 to 14, larvae were fed with powdered dry food (Sera Micron; Sera, Ludwigshafen, Germany), and afterwards with granular flake food (Tetramin ${ }^{\mathrm{TM}}$; Tetra, Melle, Germany) and newly hatched nauplii of Artemia species (Great Salt Lake Artemia Cysts, Sanders Brine Shrimp Company).

The exposure to prochloraz was carried out until 60 days post hatch, followed by a recovery period in clear water of 40 days. Additionally, control groups with and without any continuous exposure over the entire time of the experiment (100 days) were analyzed. Each treatment was run in two replicates. One hundred fertilized eggs per replicate were used at the beginning. After 30 and 60 days, 30 individuals from each tank were randomly removed for analyses. The remaining 40 fish were sampled after 100 days. Results of the 30-days sampling are not presented. In case of slight differences in the number of individuals per tank, some additional fish were removed to avoid densitydependent effects. Fish euthanized with a saturated solution of tricaine (ethyl- $m$-aminobenzoate, Sigma-Aldrich). Trunks of the fish were placed in embedding cassettes (Histosette, Neolab; Heidelberg, Germany) and fixed in modified Davidson's fixative (Romeis and Böck 2001) for subsequent histological analyses.

\section{Histology}

Samples were incubated in modified Davidsons's fixative (Romeis and Böck 2001) at $4{ }^{\circ} \mathrm{C}$ for at least $24 \mathrm{~h}$ before embedding into paraffin by a tissue processor (TP 1020, Leica Microsystems; Nussloch, Germany). Embedding into blocks was performed with a heated paraffin embedding module (EG $1140 \mathrm{H}$, Leica Microsystems) with trunks orientated ventrally to the cutting surface. Sections of the gonads with a thickness of 4-5 $\mu \mathrm{m}$ were cut with a HN 40 microtome (Reichert-Jung; Nussloch, Germany), mounted on glass slides (Langenbrinck; Emmendingen, Germany) and stained with hematoxylin-eosin (Romeis and Böck 2001) the next day. Light microscopical evaluation of the tissue sections was performed according to the Organisation for Economic Co-operation and Development (OECD) Histopathology Guidance Document (OECD 2010). Each fish was identified either as female, male, or intersex or recorded as undifferentiated.

\section{Statistics}

For statistical evaluation, data were analyzed with SigmaStat 12.0 (Statsoft-Jandel Scientific; Erkrath, Germany). Chisquare analysis was used to identify differences in sex ratio between controls and each treatment group. 
Table 1 Sex ratio (\%) of zebrafish (Danio rerio) exposed to prochloraz at 60 and 100 days post hatch (dph), data represent the total percentage of females and males per group

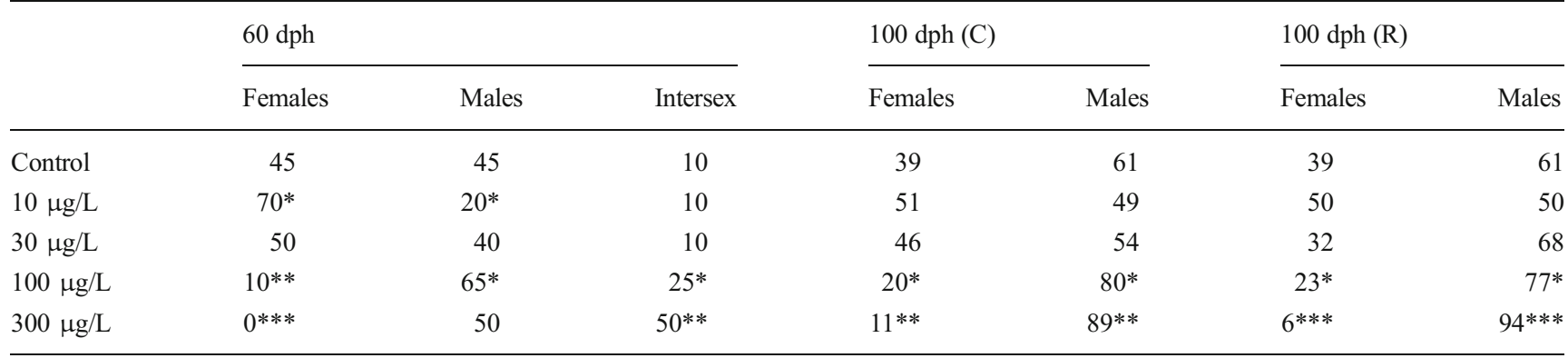

$C$ continuous exposure, $R$ 60-day exposure +40 -day recovery,

${ }^{*} p<0.05 ; * *<0.01 ; * * * p<0.001$, chi-square test

\section{Results}

No chemical analyzes were conducted, as previous experiments with the same substance in the same facility revealed high stability and small deviations from nominal concentrations as determined by chemical analyzes (Baumann 2008).

At 60 dph, 30 individuals were randomly picked out of an exposure group of 70 zebrafish. The ratio (\%) of females/
Fig. 1 Gonad histology of zebrafish at $60 \mathrm{dph}$ : a Female ovary from control group, maturity stage 2 . b Female ovary from $100 \mu \mathrm{g} / \mathrm{L}$ group, maturity stage 1. $\mathbf{c}$ Male testis from control group, maturity stage 2 . d Male testis from $300 \mu \mathrm{g} / \mathrm{L}$ group, maturity stage 1 . e Testis ova from control group, arrow indicates perinucleolar oocyte. f Testis ova from $300 \mu \mathrm{g} / \mathrm{L}$ group, arrows indicate perinucleolar oocytes
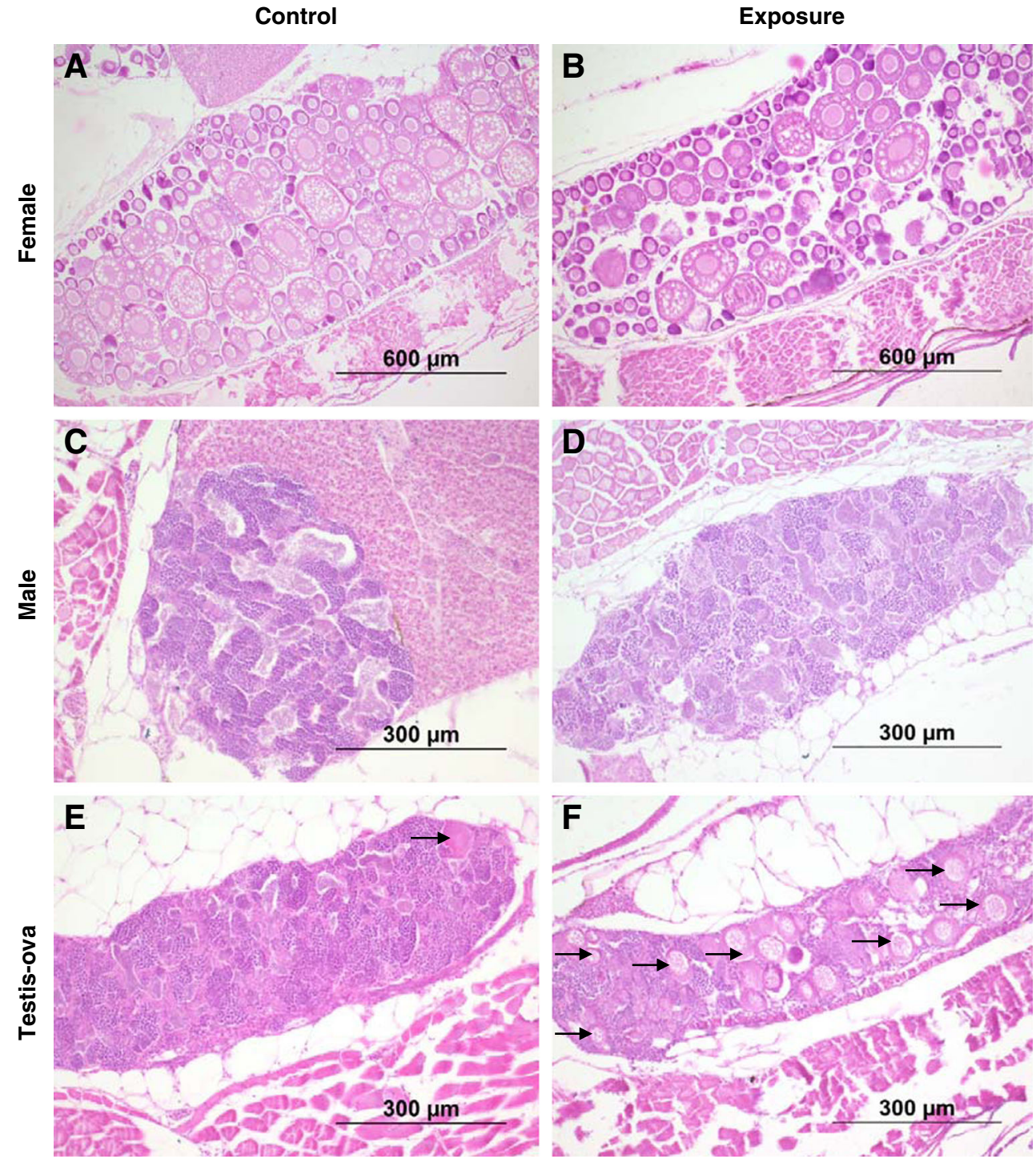
males/intersex in the control groups was 45:45:10 (Table 1). The relative amount of females decreased dose-dependently, resulting in $0 \%$ females at $300 \mu \mathrm{g} / \mathrm{L}$ prochloraz. Interestingly, while at $10 \mu \mathrm{g} / \mathrm{L}$ prochloraz, significantly more females had developed; the number of male zebrafish did not change markedly, except in the lowest concentration of $10 \mu \mathrm{g} / \mathrm{L}$ prochloraz. The most striking effect was the increased occurrence of intersex individuals after exposure to 100 and $300 \mu \mathrm{g} / \mathrm{L}$ prochloraz. Females from the exposure groups tended to have less mature ovaries (Fig. 1).

At $100 \mathrm{dph}$, the remaining 40 fish were sampled and no intersex individuals were found. The sex ratio (females/males) was 39:61 in the controls. A sex ratio of 50:50 was consistently seen at $10 \mu \mathrm{g} / \mathrm{L}$ prochloraz. A masculinizing effect was observable from $30 \mu \mathrm{g} / \mathrm{L}$ prochloraz and higher, without significant differences between continuous and discontinuous exposure. No effects on gonad maturation were evident (Fig. 2).

\section{Discussion}

The present study shows that the fungicide prochloraz has strong and irreversible masculinizing effects on sexually differentiating zebrafish. Regarding the environmental relevance of fungicide exposure, it can be concluded that prochloraz might represent a serious hazard for aquatic vertebrates and their population fitness. Nevertheless, average measured concentrations of prochloraz in European surface waters do not exceed $1 \mu \mathrm{g} / \mathrm{L}$ (Weltje 2013). The concentrations used in the present study are comparably high, but may reflect periodic or peak exposure events, where concentrations can increase much higher than usual (Probst et al. 2005). Especially during sexual differentiation, this can cause severe and irreversible adverse effects on gonad development of aquatic animals.

After 60-day exposure to prochloraz, a dose-dependent increase of intersex individuals was striking. This agrees with the findings of Kinnberg et al. (2007) and Thorpe et al. (2011),
Fig. 2 Gonad histology of zebrafish at $100 \mathrm{dph}$ : a Female ovary from control group, maturity stage 4 . b Male testis from control group, maturity stage 3. c Female ovary from $100 \mu \mathrm{g} / \mathrm{L}$ exposure group, maturity stage 4 . d Male testis from $300 \mu \mathrm{g} / \mathrm{L}$ exposure group, maturity stage 3 . e Female ovary from $300 \mu \mathrm{g} / \mathrm{L}$ recovery group, maturity stage 4 . $f$ Male testis from $100 \mu \mathrm{g} / \mathrm{L}$ recovery group, maturity stage 3
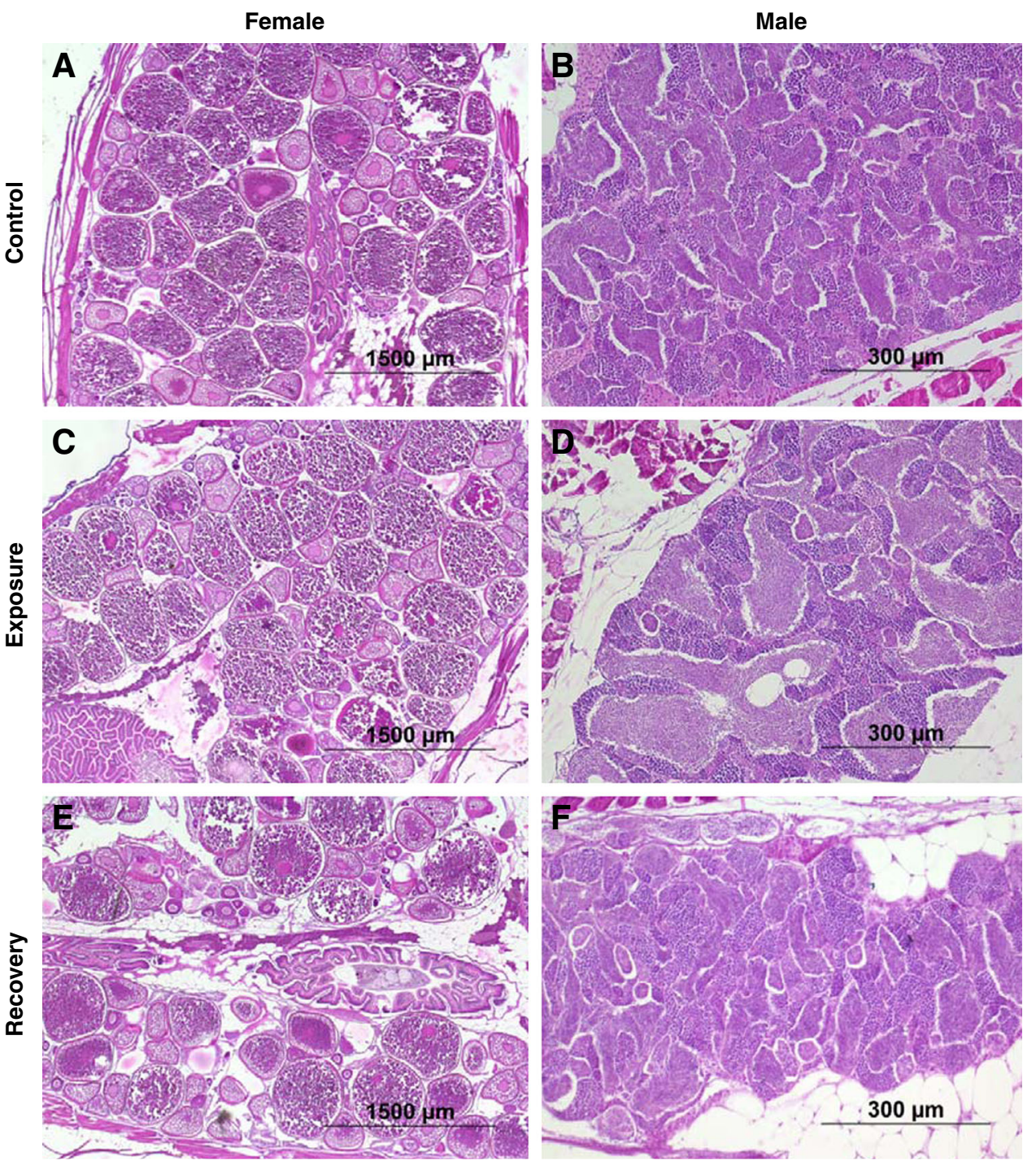
who also observed high occurrence of intersex gonads after prochloraz exposure during sexual differentiation of zebrafish. Moreover, they also reported masculinization of sex ratios and inhibited gonad maturation of females, which was also observed in the present study.

Zebrafish is a protogynic fish species, i.e., all fish first develop immature female gonads, approximately $50 \%$ of which will later transform into testes in genetic males (Takahashi 1977). This transformation is a process simultaneous to degeneration of immature oocytes and development and maturation of testicular tissue. Consequently, intersex gonads are part of the normal sexual differentiation of zebrafish males, known as "juvenile hermaphroditism" (Maack and Segner 2003). Therefore, the high percentage of intersex gonads after 60 days of exposure to prochloraz can be interpreted as retardation in the development of genetic males, possibly due to the anti-androgenic effects of prochloraz. Nevertheless, it is known that prochloraz elicits multiple modes of action that may cover each other (Vinggaard et al. 2006; Rime et al. 2010). In fact, at the highest concentration of prochloraz, no single female individual was found, which probably indicates a surplus of testosterone resulting from the aromatase-inhibiting effects of prochloraz. Since molecular mechanisms of sexual differentiation in zebrafish are not yet fully understood (Jørgensen et al. 2008; Orban et al. 2009; Tokarz et al. 2013), this interpretation remains to be certified.

So far, environmental factors seem to be the key regulators of zebrafish sex determination (Dranow et al. 2013). Recently, a communication has been published about a putative sex chromosome in zebrafish (Anderson et al. 2012), but further research is needed to confirm this hypothesis, as differences among strains were found. Another hint for masculinization, however, is that no intersex individuals were found at $100 \mathrm{dph}$. This indicates that development of intersex gonads due to prochloraz exposure at $60 \mathrm{dph}$ was not permanent and that these individuals probably further developed into functional males. This is mirrored in the sex ratio at $100 \mathrm{dph}$; a concentration-related effect could be determined after exposure to 100 and $300 \mu \mathrm{g} / \mathrm{L}$ prochloraz, with a male dominance of 77 $94 \%$. This is in line with results from previous studies (Holbech et al. 2012; Kinnberg et al. 2007) and proved to be not reversible through the recovery period, showing that masculinization of developing zebrafish is an irreversible process. The same effect was found in a previous study with the androgen 17 $\beta$-trenbolone (Baumann et al. 2014a), where the same exposure scenario was studied. Following exposure to this strong androgen, zebrafish were not able to recover from the masculinizing effects, which resulted in all-male populations in the highest exposure groups with or without recovery period. As a conclusion, treatment with androgenic or aromataseinhibiting EDCs during sexual differentiation of zebrafish leads to irreversible masculinization of gonad development. Similar effects have already been observed in other studies with androgens (Larsen and Baatrup 2010; Morthorst et al. 2010) and aromatase inhibitors (Fenske and Segner 2004).

In contrast, exposure to estrogens such as $17 \beta$ ethinylestradiol is mostly reversible (Baumann et al. 2014b; Fenske et al. 2005; Larsen et al. 2009; Nash et al. 2004; Schäfers et al. 2007). The underlying mechanism for the difference between the reversibility of feminization and masculinization by EDCs could be the loss of primordial germ cells (PGCs) during the development of testis tissue in zebrafish. This hypothesis was raised by Morthorst et al. (2010) and has not been refuted yet, even though inconsistencies in literature exist. PGCs are progenitors of gametes and differentiate either into eggs or sperms during sexual development (Saito et al. 2008). If PGCs are absent or ablated, only testis development is possible, since ovaries cannot develop without the presence of PGCs (Dranow et al. 2013; Slanchev et al. 2005; Uchida et al. 2002). Slanchev et al. (2005) could show that PGCs are also important for general gonad survival, which would indicate that testis tissue would not be able to persist for a longer period, e.g., until $100 \mathrm{dph}$. In contrast, Siegfried and Nüsslein-Volhard (2008) were able to show that germ line-deficient zebrafish are able to develop and maintain testis tissue for longer periods. Germ line-deficient zebrafish even display male coloration and male behavior, indicating that steroid hormones produced by the testis are sufficient to support masculinization of the whole organism (Siegfried and Nüsslein-Volhard 2008). Therefore, we assume that the exposure to androgens or aromatase inhibitors causes persistent testis development in genetic females due to PGC loss. As a consequence, later development of ovaries after depuration is impossible. In contrast, cessation of estrogenic exposure allows normal development of testis tissue in genetic males that were feminized (Baumann et al. 2014b). Consequently, masculinization of genetic zebrafish females represents a one-way development, whereas feminization of genetic zebrafish males can be reconverted. Regarding the extensive use of zebrafish in risk assessment of potential EDCs (Scholz and Klüver 2009; Segner 2009), much more research concerning its sexual development is still required to understand the basic mechanisms underlying this phenomenon.

\section{References}

Anderson JL, Rodriguez Mari A, Braasch I, Amores A, Hohenlohe P, Batzel P, Postlethwait JH (2012) Multiple sex-associated regions and a putative sex chromosome in zebrafish revealed by RAD mapping and population genomics. PLoS One 7:e40701

Ankley GT, Bencic DC, Cavallin JE, Jensen KM, Kahl MD, Makynen EA, Martinovic D, Mueller ND, Wehmas LC, Villeneuve DL (2009) Dynamic nature of alterations in the endocrine system of fathead minnows exposed to the fungicide prochloraz. Toxicol Sci 112:344 353 
Baumann L (2008) Effects of endocrine disruptors in zebrafish (Danio rerio) as revealed with the fish sexual development test. MSc thesis, Department of Zoology, University of Heidelberg, 102 pp.; http:// archiv.ub.uni-heidelberg.de/volltextserver/13746/

Baumann L, Holbech H, Keiter S, Kinnberg KL, Knörr S, Nagel T, Braunbeck T (2013) The maturity index as a tool to facilitate the interpretation of changes in vitellogenin production and sex ratio in the fish sexual development test. Aquat Toxicol 128-129:34-42

Baumann L, Knörr S, Keiter S, Nagel T, Rehberger K, Volz S, Oberrauch S, Schiller V, Fenske M, Holbech H, Segner H, Braunbeck T (2014a) Persistence of endocrine disruption in zebrafish (Danio rerio) after periodic exposure to the androgen $17 \beta$-trenbolone. Environ Toxicol Chem. doi:10.1002/etc.2698

Baumann L, Knörr S, Keiter S, Rehberger K, Volz S, Schiller V, Fenske M, Holbech H, Segner H, Braunbeck T (2014b) Reversibility of endocrine disruption in zebrafish (Danio rerio) after periodic exposure to the estrogen 17 $\alpha$-ethinylestradiol. Toxicol Appl Pharmacol 278:230-237

Belenguer V, Martinez-Capel F, Masia A, Pico Y (2014) Patterns of presence and concentration of pesticides in fish and waters of the Júcar River (Eastern Spain). J Hazard Mat 265:271-279

Brande-Lavridsen N, Christensen-Dalsgaard J, Korsgaard B (2010) Effects of ethinylestradiol and the fungicide prochloraz on metamorphosis and thyroid gland morphology in Rana temporia. Open Zool J 3:7-16

Dranow D, Tucker R, Draper B (2013) Germ cells are required to maintain a stable sexual phenotype in adult zebrafish. Dev Biol 376:43-50

Fenske M, Segner H (2004) Aromatase modulation alters gonadal differentiation in developing zebrafish (Danio rerio). Aquat Toxicol 67: $105-126$

Fenske M, Maack G, Schäfers C, Segner H (2005) An environmentally relevant concentration of estrogen induces arrest of male gonad development in zebrafish Danio rerio. Environ Toxicol Chem 24:1088-1098

Holbech H, Kinnberg KL, Brande-Lavridsen N, Bjerregaard P, Petersen GI, Norrgren L, Orn S, Braunbeck T, Baumann L, Bomke C, Dorgerloh M, Bruns E, Ruehl-Fehlert C, Green JW, Springer TA, Gourmelon A (2012) Comparison of zebrafish (Danio rerio) and fathead minnow (Pimephales promelas) as test species in the fish sexual development test (FSDT). Comp Biochem Physiol Toxicol Pharmacol CBP 155:407-415

Johnston G, Dawson A, Walker CH (1996) Effects of prochloraz and malathion on the red-legged partridge: a semi-natural field study. Environ Poll 91:217-225

Jørgensen A, Morthorst JE, Andersen O, Rasmussen LJ, Bjerregaard P (2008) Expression profiles for six zebrafish genes during gonadal sex differentiation. Reprod Biol Endocrinol 6:25

Kinnberg K, Holbech H, Petersen GI, Bjerregaard P (2007) Effects of the fungicide prochloraz on the sexual development of zebrafish (Danio rerio). Comp Biochem Physiol Toxicol Pharmacol CBP 145:165-170

Larsen MG, Baatrup E (2010) Functional behavior and reproduction in androgenic sex reversed zebrafish (Danio rerio). Environ Toxicol Chem 29:1828-1833

Larsen MG, Bilberg K, Baatrup E (2009) Reversibility of estrogenic sex changes in zebrafish (Danio rerio). Environ Toxicol Chem 28: $1783-1785$

Liu C, Zhang X, Deng J, Hecker M, Al-Khedhairy A, Giesy JP, Zhou B (2011) Effects of prochloraz or propylthiouracil on the cross-talk between the HPG, HPA, and HPT axes in zebrafish. Environ Sci Technol 45:769-775

Maack G, Segner H (2003) Morphological development of the gonads in zebrafish. J Fish Biol 62:895-906

Mnif W, Hassine AI, Bouaziz A, Bartegi A, Thomas O, Roig B (2011) Effect of endocrine disruptor pesticides: a review. Int J Environ Res Publ Health 8:2265-2303

Morthorst JE, Holbech H, Bjerregaard P (2010) Trenbolone causes irreversible masculinization of zebrafish at environmentally relevant concentrations. Aquat Toxicol 98:336-343
Nash JP, Kime DE, Van der Ven LTM, Wester PW, Brion F, Maack G, Stahlschmidt-Allner P, Tyler CR (2004) Long-term exposure to environmental concentrations of the pharmaceutical ethynylestradiol causes reproductive failure in fish. Environ Health Persp 112:1725-1733

OECD (2010) Guidance document on the diagnosis of endocrine-related histopathology in fish gonads. OECD Series on Testing and Assessment No. 123. Paris, France: Organization for Economic Cooperation and Development

Orban L, Sreenivasan R, Olsson PE (2009) Long and winding roads: testis differentiation in zebrafish. Mol Cell Endocrinol 312:35-41

Probst M, Berenzen N, Lentzen-Godding A, Schulz R (2005) Scenariobased simulation of runoff-related pesticide entries into small streams on a landscape level. Ecotoxicol Environ Saf 62:145-159

Rime H, Nguyen T, Bobe J, Fostier A, Monod G (2010) Prochlorazinduced oocyte maturation in rainbow trout (Oncorhynchus mykiss), a molecular and functional analysis. Toxicol Sci 118:61-70

Romeis B, Böck P (2001) Mikroskopische Technik. Urban und Schwarzenberg, Munich, $697 \mathrm{pp}$

Saito, T., Goto-Kazeto, R., Arai, K. and Yamaha, E. (2008) Xenogenesis in teleost fish through generation of germ-line chimeras by single primordial germ cell transplantation. Biol Reprod 78:159-166

Schäfers C, Teigeler M, Wenzel A, Maack G, Fenske M, Segner H (2007) Concentration- and time-dependent effects of the synthetic estrogen, $17 \alpha$-ethinylestradiol, on reproductive capabilities of the zebrafish, Danio rerio. Toxicol Environ Health A 70:768-779

Scholz S, Klüver N (2009) Effects of endocrine disrupters on sexual, gonadal development in fish. Sex Dev 3:136-151

Segner H (2009) Zebrafish (Danio rerio) as a model organism for investigating endocrine disruption. Comp Biochem Physiol Part C 149:187-195

Siegfried KR, Nüsslein-Volhard C (2008) Germ line control of female sex determination in zebrafish. Dev Biol 324:277-287

Slanchev, K., Stebler, J., de la Cueva-Mendez, G. and Raz, E. (2005) Development without germ cells: the role of the germ line in zebrafish sex differentiation. Proce Nat Ac Sci USA 102:4074-4079

Swan SH, Kruse RL, Liu F, Barr DB, Drobnis EZ, Redmon JB, Wang C, Brazil C, Overstreet JW (2003) Semen quality in relation to biomarkers of pesticide exposure. Environ Health Persp 111:14781484

Takahashi H (1977) Juvenile hermaphroditism in the zebrafish, Brachydanio rerio. Bull Fac Fish Hokkaido Univ 28(2):57-65

Thorpe KL, Pereira ML, Schiffer H, Burkhardt-Holm P, Weber K, Wheeler JR (2011) Mode of sexual differentiation and its influence on the relative sensitivity of the fathead minnow and zebrafish in the fish sexual development test. Aquat Toxicol 105: $412-420$

Tokarz J, Möller G, Hrabe de Angelis M, Adamski J (2013) Zebrafish and steroids: what do we know and what do we need to know? J Steroid Biochem Mol Biol. doi:10.1016/j.jsbmb.2013.01.003

Uchida, D., Yamashita, M., Kitano, T. and Iguchi, T. (2002) Oocyte apoptosis during the transition from ovary-like tissue to testes during sex differentiation of juvenile zebrafish. Exp Biol 205:711-718

Vinggaard AM, Hass U, Dalgaard M, Andersen HR, Bonefeld-Jorgensen E, Christiansen S, Laier P, Poulsen ME (2006) Prochloraz: an imidazole fungicide with multiple mechanisms of action. Int $\mathbf{J}$ Androl 29:186-192

Weidner IS, Moller H, Jensen TK, Skakkebaek NE (1998) Cryptorchidism and hypospadias in sons of gardeners and farmers. Environ Health Persp 106:793-796

Weltje L (2013) No proof of synergy at environmentally realistic concentrations of prochloraz and esfenvalerate - a reaction on "Synergy in microcosms with environmentally realistic concentrations of prochloraz and esfenvalerate" by Bjergager et al. Aquat Toxicol 101:412-422, Aquat. Toxicol. 140-141: 466-468 